\title{
Liquidity, Default and the Interaction of Financial Stability and Monetary Policy ${ }^{1}$
}

By

M. Udara Peiris ${ }^{2}$, Dimitrios P. Tsomocos ${ }^{3}$ and Alexandros P. Vardoulakis ${ }^{4}$

This paper is dedicated to Charles Goodhart, a genuine thinker, a remarkable political economist and above all an honourable human being.

\begin{abstract}
$\underline{\text { ABSTRACT }}$
"Default is to macro-economics what sin is to theology: regrettable but central and essential". The contemporaneous assessment of both liquidity and default within a framework of missing financial markets, multiple currencies, heterogeneous economic actors (i.e., investors, firms and intermediaries) and multiple externalities is warranted for analysing the interplay of financial and price stability. Thus, the complementarity and substitutability of regulatory and monetary policies can be identified and dissected. The optimal policy mix may be subsequently determined given the objectives of the fiscal and monetary authorities.
\end{abstract}

\footnotetext{
${ }^{1}$ The views expressed in this paper are those of the authors and do not necessarily represent those of Federal Reserve Board of Governors or anyone in the Federal Reserve System. We would also like to thank Charles Goodhart, Philipp Hartmann, Haizhou Huang, Nuwat Nookhwun, Theofanis Papamichalis, Dirk Schoenmaker, Xuan Wang, Geoffrey Wood, Ji Yang, and seminar participants at the L.S.E. conference in honour of Charles Goodhart," The Life of a Central Banker, " for helpful comments. However, all remaining errors are ours. ${ }^{2}$ International College of Economics and Finance, National Research University-Higher School of Economics, Moscow, Russia; upeiris@hse.ru. Peiris was funded within the framework of the Basic Research Program at the National Research University Higher School of Economics (HSE) and by the Russian Academic Excellence Project '5-100'.

${ }^{3}$ Saïd Business School and St. Edmund Hall, University of Oxford, United Kingdom; dimitrios.tsomocos@sbs.ox.ac.uk.

${ }^{4}$ Board of Governors of the Federal Reserve System, United States; alexandros.vardoulakis@frb.gov.
} 


\section{Introduction}

Liquidity and default have frequently been regarded as two separable concepts. Our view, instead, is that for the most interesting and important aspects of financial stability issues, they are inherently intertwined. Credit risk affects the ease with which economic agents/institutions can raise funds to meet their liquidity needs, and market illiquidity can exacerbate solvency concerns. Indeed, the interplay of liquidity and default can justify fiat money, based on the (tax) power of government, as the stipulated mean of exchange. The mere presence of a monetary sector without the possibility of endogenous default or any other friction in equilibrium will become a veil without affecting real trade and, eventually, final equilibrium allocations. Our work with Charles Goodhart has focused on the importance of default in macroeconomic analysis, which has not been until recently fully appreciated as much as other frictions, such as sticky prices or search frictions (see for example, Bhattacharya, Goodhart, Tsomocos and Vardoulakis, 2015, Goodhart, Sunirand and Tsomocos, 2004 and 2006, Goodhart, Kashyap, Tsomocos and Vardoulakis (2012 and 2013, Goodhart, Peiris and Tsomocos, 2013 and 2016, Goodhart, Peiris, Tsomocos and Vardoulakis, 2010 and Goodhart, Tsomocos and Vardoulakis, 2010) .

Inevitably, concerns about liquidity and default interact. The original idea that the start of the financial crisis in August 2007 was just a liquidity problem, though a widely shared view at the time, was simplistic. The initial economic shock arising from the US housing market raised the prospect of a higher probability of default, but most importantly led to a vicious spiral where default concern led to a fall in asset prices. This fall in asset prices then reinforced concerns about banks' and other financial intermediaries' solvency, and this further reduced liquidity in a range of asset markets, with a variety of self-amplifying spirals then bringing the whole financial system to its knees. Lack of liquidity dries up key financial markets, thus preventing institutions from restructuring their portfolios, adapting their strategies, and steering away from potential dangers caused by exogenous economic shocks. In turn, defaults start accumulating, and the domino effect leads to further reductions in liquidity and ultimately causes financial institutions, corporations, and other non-financial bodies to fail to meet their contractual obligations. 
Under the presence of multiple externalities and the evolving nature of markets, in particular for short-term funding, the forthcoming regulatory architecture should recognise that there are markets that are "too important to fail" and not only banks that are "too big to fail". Hence, regulation, and policy more generally, should also be focussed on "systemic markets" as well as "systemic institutions".

The ability to adjust monetary policy appropriately to economic conditions requires measurement of inflation and output growth. Likewise, maintenance of financial stability requires equivalent measures of financial fragility. Such measures could be used as a yardstick to assess the success of regulatory policy.

This paper provides a summary of our work with Charles Goodhart on bringing financial stability and banking institutions into macroeconomic analysis to answer a variety of questions. Section 2 describes some basic modelling elements that make the interaction of default and liquidity interesting, while maintaining the General Equilibrium spirit of the analysis. Section 3 summarizes our efforts to introduce these interactions in mainstream DSGE models that can be easily calibrated and used closely for policy analysis. In section 4 we describe attempts to incorporate more elaborate banking sectors in General Equilibrium, which have a number of important real economic functions generating multiple externalities. The ability of macroprudential regulation to tackle these market failures is also discussed. Finally, section 5 concludes.

\section{A model to analyse financial fragility}

The key components when building a model to analyse financial stability should include:

1. Inter-temporal decisions (as banks facilitate consumption smoothing demands of customers).

2. Uncertainty in the future (as banks face risk of maturity mismatches and uncertainty in loan portfolio value over time).

3. Liquid wealth or money (as the scarcity of liquidity generates costs in financial intermediation). 
4. Endogenous default (as the actions of households and banks jointly determine aggregate financial stability conditions and, consequently, financial distress).

5. Incomplete risk sharing (as financial stability conditions affect welfare).

The suite of models that we have been working on over the last 20 years have attempted to combine these elements within a single coherent framework and used it to address several issues: procyclicality of the Basel Accord (Catarineu-Rabell, Jackson and Tsomocos ,2005), collateral, money and default (Goodhart, Tsomocos and Vardoulakis ,2010b, Peiris and Vardoulakis, 2015, and Lin, Tsomocos and Vardoulakis, 2016), Minsky's financial instability hypothesis, risk-taking and excessive leverage (Bhattacharya, Goodhart, Tsomocos and Vardoulakis, 2015), international capital flows (Goodhart, Peiris and Tsomocos ,2013b, and Peiris and Tsomocos ,2015), dividend restrictions and financial regulation (Goodhart et. al., 2010a, and Goodhart et. al., 2013a), precautionary savings and default (Peiris and Vardoulakis, 2013), monetary policy and debt renegotiation (Goodhart, Peiris and Tsomocos, 2016).

\section{Basic Economic Environment}

There are multiple household-types that differ, at least, in their non-financial income stream and desire to smooth consumption. Households conduct financial transactions through a banking system composed of multiple bank-types that differ, at least, in the balance sheet characteristics they accrue. Surplus households make deposits at banks that, in turn, extend funds to deficit households in the form of commercial or consumer loans and mortgages. There also exists an interbank market where banks with excess liquidity extend credit to deficit banks. When loans and deposits come due, fundamental uncertainty in the economy generates incentives for debtors to default. Households may suffer income or wealth losses which increase the marginal cost of repayment. This then is contrasted with the marginal costs of default, modelled as non-pecuniary (e.g., reputation) costs incurred by defaulting on the volume of debt. Individual optimality results in an endogenous default rate. Alternatively, if debt is secured by collateral such as housing, fluctuations in the price level or the relative value of the collateralised good, may result in default. Banks face similar incentives for the loans obtained from the interbank market. As a consequence, default from one sector is transmitted through the banking sector to the entire economy. 
All transactions require fiat money the creation of which is a monopoly of the Central Bank. Liquid fiat money is obtained by exchanging illiquid debt with the central bank, at a cost. Expanding the amount of money in the economy reduces the cost of liquidity, or equivalently, increases the liquidity of private assets and household endowments, and increases the efficiency of all transactions. Importantly, infinite liquidity may not be optimal as the limiting economy itself is inefficient due to market incompleteness and agent heterogeneity.

The model is summarised by three key equations:

1) The Quantity Theory of Money (which summarises the intra-temporal relationship between liquidity, the nominal price level and real trade);

2) The Term Structure of Interest Rates (which summarises the inter-temporal transmission of shocks);

3) The On the Verge condition (which summarises the marginal propensities of households and banks to default).

We will now sketch a version of the Tsomocos (2003) and Goodhart, Sunirand and Tsomocos (2006) models.

\section{The Model}

It is an exchange economy with multiple commodities. There are two periods, where there is certainty in the first and uncertainty in the second. There are both real (commodity) and financial trades in the first period while in the second there are real trades and intertemporal financial trades are settled. Households borrow and deposit with the banking system while banks also conduct financial trade amongst themselves to obtain an optimal portfolio. The Central Bank participates in the interbank market by injecting money and affecting the interbank rate. Banks are subject to Capital Adequacy Requirements (CARs) set by a regulator and penalties are imposed upon violations of CARs. Banks are owned by households and are liquidated at the end of the second period with profits and assets distributed to shareholders. Households and banks incur private (non-pecuniary) costs of defaulting on their financial obligations. We model the incentive for avoiding default by penalising agents and banks proportionately to the size of default. Both banks and 
households are allowed to default on their financial obligations, but not on commodity deliveries.

In the first period, households and banks observe current prices and form correct (rational) expectations of prices in the (uncertain) second period. Households are heterogeneous with respect to their endowment/income stream and risk attitudes and hence in their propensities for default. There are also several bank types, heterogeneous with respect to risk/return preferences and initial capital, and having a captive or unique relationship with particular household types. In other words we introduce limited access to consumer credit markets, with each household assigned (by history and custom) to borrow from a predetermined bank. This feature results in a distribution of interest rates offered to depositors and debtors in the economy.

\section{Definition of Financial Stability}

The model offers a model-based definition of financial fragility that is characterised by substantial default of a 'number' of households and banks (i.e., a liquidity 'crisis'), without necessarily becoming bankrupt, and a significant decline in the aggregate profitability of the banking sector (i.e., a banking 'crisis'). A natural question is why either one of the conditions is not sufficient by itself to constitute a financially fragile regime. Increased default without reduced profitability might be an indicator of increased volatility and risk taking without necessarily leading to financial instability. For example, both the mean and variance of return might have risen. On the other hand, lower bank profitability without increased default might be an indicator of a recession in the real economy and not of financial vulnerability. It is the combination of both conditions that destabilises the financial system and may produce financial crises. This definition is sufficiently flexible enough to encompass most of the recent episodes of financial fragility. For example, the Japanese crisis may be thought of as an example of the Keynesian liquidity trap. The Mexican crisis of the early $1990 \mathrm{~s}$ is a classic example of liquidity and banking crisis. The late 1990s East Asian crisis was characterised by a banking crisis and economic recession as well as extensive default. Finally, the Russian crisis, the Texas Banking crisis, and the US Stock Market crash of 1987 conformed to the characterisation of a financially fragile regime generated by liquidity shortages, extensive default and declines in bank profitability. 


\section{Results}

In this model, both regulatory and monetary policies are non-neutral and arises from the presence of incomplete financial markets and liquidity constraints (since all trade is mediated with liquid assets i.e., money). Monetary and regulatory policies influence the distribution of income and wealth amongst heterogeneous agents and hence have real effects. Some other main results are:

- the central bank controls the overall liquidity of the economy and such liquidity, as well as endogenous default risks, determines interest rates;

- nominal changes (i.e., changes in monetary aggregates) affect both prices and quantities; and

- the nominal interest rate is equal to the real interest rate plus the expected rate of inflation (Fisher effect).

From an analysis of a set of comparative statics exercises, using the model, a number of implications arise.

First, in an economic environment in which capital constraints are binding, more expansionary monetary policy may lead banks in some cases to adopt riskier strategies. ${ }^{5}$ The liquidity injected by the central bank can be used by some banks to expand their loans to the non-financial private sector. This can lead to a rise in the size of their assets, relative to their capital base, thus worsening their capital position. It is a well-known stylised fact that financial crises are often caused by excessive, and unwise, lending in the upswing of the cycle, ${ }^{6}$ which then leads to non-performing loans and failures in a subsequent downturn, should an adverse shock occurs. Thus expansionary policies causing 'excessive' loan expansion can lead to financial fragility.

\footnotetext{
${ }^{5}$ This does not imply that a deflationary bias is optimal. Inflation targeting is not considered and such a regime can be approximated by fixing money supply.

${ }^{6}$ See, for example, Borio and Lowe (2002).
} 
Second, agents who have more investment opportunities can deal with negative shocks more effectively by restructuring their investment portfolios expeditiously. Such restructuring may put even more pressure on other agents with a more restricted set of investment opportunities. For example, banks which can move into security investments when there is an adverse shock to customer borrowing may make market conditions even worse for banks which cannot so diversify. Put differently, banks with more degrees of freedom may transfer various externalities to smaller ones that have fewer alternatives in their choice sets. This result has various implications. Amongst them, banks with asset portfolios that are not well diversified tend to follow a countercyclical credit extension policy in the face of a tightening of regulatory standards in the loan market (e.g.,tighter loan risk weights) during an economic downturn. In contrast, banks that can quickly restructure their portfolio tend to reallocate their investments away from the loan market, thus following a procyclical credit extension policy.

Third, an improvement such as a positive productivity shock, which is concentrated in one part of the economy, does not necessarily improve the overall welfare and profitability of the economy.

The last two insights relate to the innovative feature of the model of incorporating heterogeneous agents; banks and bank borrowers are not all alike. This has some, fairly obvious, implications. The result of a shock depends on the particular sector of the economy which is affected and it can often shift the distribution of income, and welfare, between agents in a complex way, which is hard to predict in advance.

\section{Default and DSGE Models}

Martin Shubik described money as an "institutionalised symbol of trust" (Shubik, 1999), and Kiyotaki and Moore (2002) coined a nice phrase, "Evil is the root of all money". And they are correct in this. If everyone always repaid all their debts with certainty, then there would be no need for money, most financial instruments, nor intermediaries like banks. All that 
would be needed to complete a transaction would be a handshake and the acknowledgement that the buyer is indebted to the seller. Of course, the good that the seller would like to receive at some future date would not necessarily be what the buyer could offer, but that discrepancy could easily be resolved in complete financial markets.

This proposition already indicates one problem with the assumption that no one defaults, which is that it must imply, as a corollary, a complete set of financial markets. But, as is already well known, a complete set of financial markets not only does not exist but would allow for an Arrow-Debreu Walrasian general equilibrium in which all transactions could be established at time zero. That would prevent default arising as a result of future bad outcomes, since all such potential outcomes could be hedged in the complete financial markets.

Perhaps even more importantly, a no default assumption, or equivalently the transversality condition in infinite horizon models ${ }^{7}$, would require all agents to be completely and perfectly moral, in the sense that they would never abrogate their contractual obligations. Thus, if you were to take a taxi, even though you would certainly never meet that taxi driver again, you would always pay her. If the ordinary person could get out of repaying her due debt with impunity, then she would!

The upshot of our analysis is that liquidity and default are endogenous variables that are codetermined in equilibrium. Hence, it is an oxymoron to conduct monetary and financial stability analysis when we are treating them as exogenous in the form, for example, of exogenously set credit spreads!

Incorporating default into the DSGE framework would also have the side-benefit of restoring a union between macro theory and finance, since the probability of default is a prime element within finance. While we in finance are not wedded to DSGE models, such DSGE models represent a useful discipline and framework and are also the workhorse of most macro modelling. So, our priority ought to be to embed an analytical approach to default within an otherwise standard DSGE model. Doing so has the great advantage that it provides a rationale for the use of money. If you think that the buyer of your product may not meet

\footnotetext{
${ }^{7}$ With debt due infinitely in the future, or rolled over indefinitely at face-value.
} 
his resultant debt, you will ask him to pay on the nail, i.e., it provides a rationale for the cash or liquidity-in-advance ${ }^{8}$ requirement. Similarly, the main role for banks is to be able to assess probabilities of default better than you or I. Thus, we need them in order to be able to reduce risk-premia and lower the spread between bid and ask rates. Hence, banks become an essential element of any model incorporating default and incomplete asset markets.

Nevertheless, incorporating default into a DSGE model makes the analytical exercise significantly more complex. In particular, one can no longer use the representative agent model, because only a (small) proportion of agents default at any time. The inclusion of heterogeneous agents, banks, liquidity and default greatly increases the scale of parameterisation and the dimension of such models. Nevertheless, such an extended model would at least be micro-founded, whereas a lot of frictions in most DSGE models are not. Moreover, it would have the benefit of having a proper foundation for the inclusion of money and financial intermediaries within the system. Consequently, a non-trivial quantity theory of money would obtain whereby when nominal changes occur both prices and quantities would adjust. Of course, during normal times when default is low and constant, one can ignore money as an inessential veil; but that would not help under those circumstances when default probability becomes prominent.

A DSGE model with default and money (Goodhart, Peiris and Tsomocos, 2016, and Martinez and Tsomocos, 2016) has been constructed with default and liquidity as key features. ${ }^{9}$ We can show how the working of the system changes, first just to take account of heterogeneous agents, and then to take account of the existence of potential default. Heterogeneous agents affect outcomes because of much more extensive distributional as well as wealth effects. In many simulations, some agents gain and others lose, and that makes it much more difficult to assess the welfare implications of various economic developments. When we incorporate the effect of default on our system, it has significant effects on how the economy responds to various stimuli, with some notable differences from the results of models, especially in the short and medium term, in which default is

\footnotetext{
${ }^{8}$ Martinez and Tsomocos (2016).

${ }^{9}$ See also Clerc et al. (2015) for a DSGE model with household, entrepreneur and bank defaults albeit in a real economy.
} 
assumed away, e.g. by the transversality condition. Moreover, default enables the proper assessment of the importance of collateral and the emergence of leverage cycles. Finally, incomplete financial markets allow for an active role for policy whereby welfare improving policies can be implemented.

Of course, such a model is quite complex and cannot be reduced to the three-equationreduced form guise in which most of the current DSGE models are now presented. Moreover, we do realise that the addition of a credit risk premium into the output equation enables the three-equation-reduced form to remain in disturbed times. However, such a stratagem completely undermines the assertion that such a model has proper theoretical micro-foundations. If one wants to understand what has been happening to our economies over the last few years, we do not think that there is any alternative to a modelling strategy in which both default and money are essential attributes of the working of the macroeconomy. Such a new paradigm would offer an integrated framework to address both monetary and regulatory policy.

\section{Making Macroprudential regulation operational ${ }^{10}$}

In Goodhart et al. (2012) and Kashyap et al. (2014b) we expand on the economic function that financial intermediaries play in the economy, study in detail the externalities associated with their behaviour and suggest regulation to tackle the inefficiencies. In particular, prior work suggests three theoretical channels through which intermediaries can improve welfare. One strand of thinking emphasises the role that they play in extending credit to certain types of borrowers (e.g. Diamond 1984). A second views them as vehicles for improving risk-sharing. They can do this through the liability side of their balance sheet by creating safe and risky claims (e.g. deposits and equity) against the assets that they hold (Benston and Smith 1976, Allen and Gale 1997). And the third perspective supposes that they specialise in creating liquid claims that are backed by illiquid assets (Diamond and Dybvig, 1983). We focus on two principles of financial regulation

\footnotetext{
${ }^{10}$ This section borrows material from Kashyap et al. (2014a).
} 
- Our first principle is that it is imperative to start with a general model where the financial system plays all three of these roles.

This is not true of most of the new literature on macroprudential regulation. For instance, Benes et al. (2014) have no role for liquidity provision in their set up - to be fair, very few macro models do. Without this contribution to the financial system, certain forms of instability are ruled out; for instance, funding runs can only happen if we suppose that there is a maturity mismatch between assets and liabilities.

Likewise, regulation to fix potential runs, such as proposals for narrow banking (e.g. Cochrane, 2014), also appears to be especially appealing. But if the fragility that creates the possibility of runs is not valuable on its own, of course, eliminating it would be desirable! The more challenging question is what happens if there is a fundamental underlying reason why maturity mismatches create value for some parties. In that case, regulation that stops runs for certain organisational forms may simply move activity to other unregulated entities because of the underlying legitimate demand for liquidity creation(Goodhart 2008). Or, if the regulation is fully effective at preventing runs, then the social value of the liquidity provision is lost. A suitable model should be capable of assessing these trade-offs.

- Our second principle is that intermediaries should operate in an environment where the savers who use them are forward looking, and the prices the intermediaries face adjust (endogenously) to the regulatory environment.

For example, much of the Basel Committee's regulatory agenda has focused on raising capital requirements for banks. The consequences of such regulations are very different when the banks have to offer attractive enough returns to entice savers to buy equity, than when the price of equity is unrelated to the size of a bank's balance sheet and/or the risks on that balance sheet.

We are unaware of any existing models that satisfy these two principles. So, in Kashyap et al. (2014b), we have constructed one by modifying the classic Diamond and Dybvig's (1983) framework. In their original model, banks only provide liquidity insurance to savers (by allowing depositors the option of withdrawing early), so there is no other risk-sharing or 
additional lending that takes place because of banks. Our modifications are designed so that banks also provide these services.

There are four specific changes that we make.

- First, savers can buy equity in a banking sector and save via deposits.

- Second, the banks choose to invest in safe assets or to fund entrepreneurs who have risky projects.

Together, these changes make banks' asset and liability structure interesting, and create a situation where there is some fundamental risk that cannot be diversified away.

- Third, the banks and the entrepreneurs face limited liability.

- Finally, there is a probability of a run, but unlike in Diamond and Dybvig, the decision whether to run is governed by the banks' leverage and mix of safe and risky assets.

In particular, when the banking system has more loans relative to safe assets, or more deposits relative to equity, a run is more likely. The possibility of the run reduces the incentive to lend and take risk, while limited liability pushes for excessive lending and risktaking. So, the baseline economy suffers from two problems: The destructive aspects of runs (where savers can lose money, banks can fail, and borrowers have their loans pulled), and the moral hazard problems that come from limited liability.

The banks in this world not only offer liquidity insurance with their deposits, but they offer savers a better alternative to making direct loans to entrepreneurs. This occurs because the banks start with some initial equity, which serves as a buffer in the case the entrepreneurs' projects fail; so, banks are pooling and trenching risks, and by doing so they can attract more funds to lend than the savers would be willing to risk if they could not access the banks.

The bulk of our paper explores the portfolio choices that savers and banks make in this kind of environment. One nice feature of this model is that it can be used to explore how capital regulation, liquidity regulation, deposit insurance, loan to value limits, and dividend taxes alter allocations and change the degree of run-risk and total risk-taking. Rather than focusing on very specific findings about how these interventions can matter, we mention 
here a few findings that seem likely to carry over to other models that respect our two principles.

\section{Some general findings of the model}

First, as a benchmark, we compute the portfolio allocations that a central planner would make. We find that approximating the planner's allocations with just one regulation is impossible. In this model, it takes at least two tools to overcome the two distortions. Second, the way that the various regulations change behaviour is very different, and combining some of them leads to very little improvement. Put differently, it is not correct to conclude that combining any two tools is necessarily enough to correct the two externalities in the model. Third, the interactions among the regulations are sufficiently subtle that it would be hard to guess which combinations prove to be optimal in this model.

We do not want to claim that our model is sufficiently general that the findings necessarily apply in all other models. But, attempting to assess different regulations (and to calibrate how they should be set) would be very difficult to do without consulting a range of models. Intuition helps, but at some point it runs out.

Finally, coming up with regulations that simultaneously eliminate runs and shrink total lending (and risk-taking) is hard. This happens because the usual interventions that make runs less likely either create opportunities for banks to raise more funds or take more risk, or so severely restrict the savers, banks or borrowers that one of them is made much worseoff.

We hope that these ideas will lead others to move away from small perturbations of existing DSGE models and instead consider much more fundamental changes.

\section{Concluding remarks}

In reality, the economic system is both complex and heterogeneous. In order to model it in a way that is mathematically tractable, rigorous and yet simple enough to be illuminating, economists have often tended to assume homogeneity amongst agents in the sectors 
involved. Unfortunately that prevents analysis of certain key features of financial fragility, especially those relating to interbank interactions.

Some minimum structural characteristics should be present in any model attempting to capture fundamental aspects of financial instability and correcting for multiple externalities. First, it should be multiperiod, with aggregate uncertainty and agent heterogeneity. Different actions and policy recommendations are necessary for crisis resolution depending on the structure of economic uncertainty and the impact on various economic sectors. Second, default and missing financial markets should be part of the model so as not every eventuality can be hedged; thus making regulation and policy relevant. Third, money and liquidity constraints should be explicit, since financial crises evolve from the nominal sector and subsequently spread to the real economy. Fourth, since the performance of banks is critical for the study of financial fragility and contagion, a banking sector well integrated in the model is indispensable to any modelling attempt. Finally, the regulatory framework should be clearly defined for policy and sensitivity analysis of various regulatory regimes and the associated distributional and welfare consequences. 


\section{$\underline{\text { References }}$}

F. Allen and D. Gale, 1997, "Financial Markets, Intermediaries, and Intertemporal Smoothing", Journal of Political Economy 105(3), pp. 523-546.

J. Benes, M. Kumhof and D. Laxton, 2014, “Financial Crises in DSGE Models: A Prototype Model", IMF Working Paper 14/57, International Monetary Fund.

G.J. Benston and C. W. Smith, 1976, "A Transactions Cost Approach to the Theory of Financial Intermediation", Journal of Finance 31(2), 215-231.

S. Bhattacharya, C.A.E. Goodhart D. Tsomocos, and A.P. Vardoulakis, 2015, "A Reconsideration of Minsky's Financial Instability Hypothesis", Journal of Money, Credit and Banking 47(5), pp. 931-973.

C. Borio and P. Lowe, 2002, Asset Prices, Financial and Monetary Stability: Exploring the Nexus, Bank for International Settlements, Basel, Switzerland, BIS Working Paper(114).

E. Catarineu-Rabell, P. Jackson, and D.P. Tsomocos, 2005 , "Procyclicality and the new Basel accord: banks'choice of loan rating system", Economic Theory 26, pp. 537-557.

L. Clerc, A. Derviz, C. Mendicino, S. Moyen, K. Nikolov, L. Stracca, J. Suarez, and A.P. Vardoulakis, 2015, "Capital Regulation in a Macroeconomic Model with Three Layers of Default", International Journal of Central Banking 11(3), pp. 9-63.

J.H. Cochrane, 2014 , "Towards a Run-Free Financial System," working paper.

D.W. Diamond, 1984 , "Financial Intermediation and Delegated Monitoring," Review of Economic Studies 51, pp. 393-414. 
D.W. Diamond and P.H. Dybvig, 1983 , "Bank Runs, Deposit Insurance and Liquidity”, Journal of Political Economy 91(3), 401-419.

C.A.E. Goodhart, 2008, "The Boundary Problem in Financial Regulation", National Institute Economic Review 206, pp 48 -55.

C.A.E. Goodhart, A.K. Kashyap, D.P. Tsomocos and A.P. Vardoulakis, 2012,"Financial Regulation in General Equilibrium", NBER WP 17909

C.A.E. Goodhart, A.K. Kashyap, D.P. Tsomocos and A.P. Vardoulakis, 2013a, "An Integrated Framework for Multiple Financial Regulations", International Journal of Central Banking 9(1), pp.109-143.

C.A.E. Goodhart, M.U. Peiris, and D.P. Tsomocos, 2013b , “Global Capital Imbalances and Taxing Capital Flows", International Journal of Central Banking 9(2), pp.13-45.

C.A.E. Goodhart, M.U. Peiris, and D.P. Tsomocos, 2016, “Monetary Policy vs Debt Renegotiation: A Counterfactual Analysis on Greece", Working paper.

C.A.E. Goodhart, M.U. Peiris, D.P. Tsomocos, and A.P. Vardoulakis, 2010 , “On Dividend Restrictions and the Collapse of the Interbank Market", Annals of Finance 6(4), pp. 455-473.

C.A.E. Goodhart, P. Sunirand, and D.P. Tsomocos, 2004, “A Model to Analyse Financial Fragility: Applications", Journal of Financial Stability, 27, Volume 1, 1:1-35.

C.A.E. Goodhart, P. Sunirand, and D.P. Tsomocos, 2006 , “A Model to Analyse Financial Fragility", Economic Theory 27, pp. 107-142, .

C.A.E. Goodhart, D.P. Tsomocos and A.P. Vardoulakis, 2010, "Modelling a Housing and Mortgage Crisis", in Financial Stability, Monetary Policy and Central Banking. Edited by Rodrigo A. Alfaro. Series in on Central Banking, Analysis and Economic Policies. Central Bank of Chile. 
A.K. Kashyap, D.P. Tsomocos and A.P. Vardoulakis, 2014a, "Principles for Macroprudential Regulation", Banque de France Financial Stability Review, No. 18, pp. 173-182.

A.K. Kashyap, D.P. Tsomocos and Alexandros Vardoulakis, 2014b , "How does macroprudential regulation change bank credit supply?", NBER working paper 20165.

N. Kiyotaki and J. Moore, 2002, "Evil is the Root of All Money", Clarendon Lectures, American Economic Review, Vol. 92, No. 2, pp62 -66, Papers and Proceedings.

L. Lin, D.P. Tsomocos, and A.P. Vardoulakis, 2015, "Debt Deflation Effects of Monetary Policy", Journal of Financial Stability 21, pp. 81-94.

J.-F. Martinez S. and D.P. Tsomocos, 2016, "Liquidity and Default in an Exchange Economy", working paper, Journal of Financial Stability, forthcoming.

M.U. Peiris and D.P. Tsomocos, 2015, "International Monetary Equilibrium with Default", Journal of Mathematical Economics 56, pp 47-57.

M.U. Peiris and A.P. Vardoulakis, 2013, "Savings and Default", Economic Theory 54(1), pp. 153-180.

M.U. Peiris and A.P. Vardoulakis, 2015, "Collateral and the Efficiency of Monetary Policy", Economic Theory 59(3), pp. 579-603.

M. Shubik, 1999, The Theory of Money and Financial Institutions, M.I.T. Press.

D.P. Tsomocos, 2003 , "Equilibrium Analysis, Banking, and Financial Instability", Journal of Mathematical Economics 39(5-6), pp. 619-655. 